\title{
Memórias maternas: experiências da maternidade na transição do parto doméstico para o parto hospitalar
}

\author{
Ana Paula Vosne Martins*
}

Existe mais de um roteiro para a maternidade. Aminatta Forna, 1999.

Desde o século XVIII muito se escreveu a respeito do que era considerada a mais sublime e importante missão das mulheres: a maternidade. Uma rápida verificação na base de dados da biblioteca mais próxima é suficiente para se ter uma idéia parcial do quanto este tema estimulou a pena dos autores das mais diferentes posições políticas e motivações ideológicas. São romances, livros e ensaios escritos por moralistas e religiosos e, principalmente, os tratados médicos que definiam os restritos limites da normalidade através do exercício da maternidade como forma de se atender os ditames da natureza sobre o corpo feminino. Ao longo do século XIX, conforme a profissão médica foi se consolidando e adquirindo prestígio, a vida reprodutiva das mulheres se tornou objeto de estudo nas faculdades de medicina, assim como os obstetras começaram a adentrar na cena do parto, apesar da predominância das parteiras leigas ou diplomadas no atendimento obstétrico domiciliar.

Na virada do século XIX para o XX, preocupações de ordem política, demográfica e de saúde pública estiveram na origem de uma verdadeira

* Professora do Departamento de História da Universidade Federal do Paraná e coordenadora do Núcleo de Estudos de Gênero da UFPR. 
cruzada em favor da infância, envolvendo médicos, filantropos, mulheres ativistas, religiosos e políticos dos países europeus e americanos. Dados referentes à mortalidade infantil assombravam as autoridades e os médicos, bem como ameaçavam os brios nacionalistas, especialmente na França e na Inglaterra. Era necessário estabelecer uma política de saúde e de assistência social voltada diretamente para as mães e as crianças pobres para estancar os altos índices de mortalidade infantil. É nesse contexto que são criadas maternidades, abrigos maternais, lactários, creches, jardins de infância, postos de puericultura, enfim, diferentes instituições voltadas para o atendimento à maternidade e à infância (Knibiehler, 2000; Thebaud, 1986). É também nesse momento que vêm a público os mais diferentes tipos de publicações sobre a infância, como manuais de puericultura, folhetos, seções em revistas e jornais escritas por médicos, todos procurando ensinar as mães como cuidar de si mesmas - praticando a puericultura intra-uterina - e de seus filhos, seguindo as orientações dos médicos sobre a alimentação, a higiene e as doenças infantis. Os especialistas partiam do princípio que não bastava ser mãe, era preciso saber ser mãe e, para tanto, se fazia necessário aprender com os médicos. Tem-se, portanto, uma ampla e diversificada produção especializada sobre maternidade e cuidados infantis que só cresce conforme adentramos no século XX, especialmente após a Segunda Guerra Mundial, com as publicações médicas incluindo as teorias psicológicas e as descobertas da psicanálise (Forna, 1999; Ehrenreich \& English, 2003).

Se a memória dos especialistas sobre a maternidade e a infância é bastante conhecida por pesquisadores da história das mulheres e da medicina, as memórias maternas são escassas e não tiveram o mesmo lugar de registro. Refiro-me às memórias das mulheres que viveram a experiência da maternidade na mesma época em que se produzia este imenso corpo documental e que se formulavam as primeiras políticas de saúde materno-infantil pelos Estados. A recuperação desta memória é importante não só pelo registro de uma outra perspectiva, a das mulheres que foram mães, mas também pela confrontação de ambas, pela possibilidade de se conhecer o que significou para as mulheres a maternidade, de que forma e em que condições foram mães, que influência tiveram as idéias, os valores e as teorias dos especialistas sobre suas práticas. Através da memória das mães é possível se entender o contexto da valorização da maternidade e da infância no século XX a partir de outras visões dessa experiência 
que, no conhecimento dos especialistas, parecia ser comum a todas as mulheres. As memórias maternas são narrativas da diversidade de práticas e sentimentos, antes que da unidade de uma abstrata e ideológica natureza feminina; são narrativas de como as mulheres se apropriaram das convenções sociais sobre a maternidade; de como buscaram soluções para os problemas cotidianos e também da multiplicidade de sentimentos relacionados a esta experiência de dar à luz e criar filhos.

Este artigo apresenta algumas reflexões sobre a construção das memórias maternas a partir de entrevistas realizadas com mulheres de terceira idade que atualmente vivem na cidade de Curitiba. Trata-se de parte de uma investigação mais ampla sobre a história da maternidade no Brasil pensada a partir da idéia de experiências da maternidade, ou seja, valores, práticas, políticas públicas e as memórias das mulheres que viveram esta experiência. Para selecionar as mulheres que seriam entrevistadas foi necessário conhecer o contexto de valorização da maternidade e da infância no Brasil, bem como o momento em que a maternidade passou a ser assunto de interesse do Estado, algo que se verifica a partir da década de 1930. Tem-se, a partir de então, o que denomino de processo de transição do parto doméstico para o parto hospitalar, acompanhado de uma série de mudanças graduais nos hábitos das mães, como o costume de freqüentar os consultórios de obstetras e pediatras, o uso de medicamentos e o consumo de produtos da indústria de higiene e alimentação infantil, a maior disponibilidade de acesso aos serviços públicos de saúde maternoinfantil, bem como a universalização destes serviços com a participação de instituições filantrópicas, para-estatais, patronais e de trabalhadores.

Estabelecido o contexto, defini duas gerações de mulheres que viveram esta transição no Brasil: a primeira geração é composta de mulheres que nasceram antes de 1930, portanto, mulheres que iniciaram a sua vida reprodutiva mais tardiamente entre as décadas de 1940 e 1950, ou seja, engravidaram, deram à luz e criaram os filhos no momento em que se formulavam as políticas públicas para a maternidade e a infância no país. São mulheres que hoje estão com idades superiores a 75 anos e que, na sua maioria, tiveram os filhos em casa atendidas por parteiras, não freqüentavam consultórios médicos para fazer exame pré-natal, dificilmente levavam os filhos ao pediatra e não tinham disponíveis métodos contraceptivos seguros. A segunda geração é composta pelas filhas da primeira geração, ou seja, mulheres que nasceram entre as décadas de 1940 e 1950 
e que entraram na fase reprodutiva entre as décadas de 1960 e 1970. Estas mulheres, diferentemente das suas mães, deram à luz nas maternidades, fizeram exame pré-natal, levaram os filhos aos pediatras, contaram com uma maior disponibilidade e variedade de produtos das indústrias farmacêutica, de higiene e de alimentos, além do fato importante de que entre elas estão as primeiras mulheres a integrar um movimento contínuo e crescente em busca de formação universitária e de profissionalização, bem como viveram experiências novas como o divórcio e o uso da pílula anticoncepcional.

A análise que apresento é resultado das entrevistas que foram realizadas com as mulheres da primeira geração, pois a pesquisa ainda está em desenvolvimento. São mulheres de diferentes classes sociais, de origem rural e urbana, com graus de escolaridade também diferentes e idades variando entre 77 e 92 anos. As dez entrevistas foram realizadas seguindo um roteiro de perguntas semidirigidas que abordam a infância, as atividades dos pais, o número de irmãos, a escolaridade, o trabalho, o namoro e o casamento, o acesso às informações sobre sexualidade, a gravidez, o parto, a relação com parteiras e médicos, informações sobre os cuidados com os filhos e a definição de maternidade para elas. ${ }^{1}$ Trata-se, portanto, de uma análise parcial, pois é necessário conhecer a memória das mulheres da segunda geração para se estabelecer parâmetros de comparação. Contudo, as memórias maternas das mulheres idosas apresentam elementos narrativos e versões das experiências individuais de processos sociais e culturais suficientes para se iniciar uma discussão sobre a construção da memória materna e também da metodologia da história oral.

$\mathrm{O}$ interesse pelas memórias maternas se deve, em grande parte, à minha vinculação teórica e política ao feminismo. Em pesquisa anterior havia analisado a produção médico-científica sobre o corpo feminino na obstetrícia e na ginecologia e desde então, tendo em vista a centralidade da maternidade nestes discursos, como também na vida da maioria das mulheres, percebi o quanto era importante e necessária uma abordagem histórica que incluísse a perspectiva das mães, suas experiências e sua subjetividade (Martins, 2000). Se, de uma maneira geral, as pesquisas sobre a

1 Esclareço que esta é uma pesquisa qualitativa. O objetivo não é estabelecer amostras, mas sim investigar as representações e as experiências da maternidade para um conjunto heterogêneo de mulheres. 
história das mulheres enfatizaram a produção da mitologia e das representações sobre a maternidade, é preciso também incluir outras vozes, outras construções do passado. Isso não significa que se defenda aqui uma visão purista da história oral, como se a memória das mães fosse mais verdadeira ou apresentasse uma versão mais confiável do passado que a dos especialistas. Trata-se, tão somente, de uma mudança de perspectiva, ou seja, a memória das mães ilumina não só a subjetividade feminina, mas também apresenta elementos que permitem compreender as complexas relações entre a memória, a consciência e as ideologias de gênero (Sangster, 2003).

A abordagem feminista da maternidade que tem como referências as experiências femininas e a construção da memória deve muito à filósofa Sarah Ruddick (1989; 1994). Seu trabalho se fundamenta na idéia de que a maternidade não envolve somente emoções conflitantes, mas é uma prática que engendra um modo sofisticado de pensar, incluindo todas as operações lógicas e racionais sobre atividades de cuidado e de relação com os outros, levantando importantes considerações sobre a produção da subjetividade feminina e a natureza política das atividades relacionadas com o cuidado dos outros (Tronto, 1996). Ruddick comenta que as análises feministas sobre a maternidade tendem a falar das mães a partir da perspectiva das filhas, especialmente as autoras ligadas à psicanálise. Adaptando ao seu trabalho sobre a maternidade uma concepção prática da razão, Ruddick defende a adoção da perspectiva das mães no sentido de entender o pensamento materno: “[...] o pensamento materno não é uma raridade. A maternidade é um projeto complexo que envolve muitas pessoas, prolongado no tempo, carregado de conflitos, que requer cooperação e está imerso em questões fundamentais como a sexualidade, a morte e a responsabilidade. Por que as mães não pensariam, não exerceriam uma atividade intelectual?" (Ruddick, 1994, p. 34). Cabe ressaltar que Sarah Ruddick não está propondo uma abordagem essencialista da maternidade. Pelo contrário, sua análise se opõe a qualquer tipo de determinismo, desnaturalizando a maternidade e as atividades de cuidado com os outros ao defender que estas experiências tão inter-relacionadas são experiências políticas obscurecidas e desvalorizadas pela oposição entre público e privado.

Embora a maternidade tenha sido um tema recorrente na reflexão e na produção do pensamento feminista no século XX, as abordagens são bastante diversificadas, bem como o posicionamento político em relação 
à questão. No início do século XX a maternidade era ainda reconhecida como fonte da dignidade e da superioridade moral das mulheres. Para as feministas que lutavam pelos direitos das mulheres no período entre guerras, a maternidade era um direito, mais do que um dever. Já para as leitoras de Virginia Wolff, Simone de Beauvoir e Betty Friedan como também para as mulheres que viveram os anos da revolução sexual, a maternidade era uma das peças mais importantes para se entender a opressão feminina.

A partir das décadas de 1970 e 1980 as pesquisadoras feministas se esforçaram para desconstruir a mitologia da maternidade fazendo a crítica histórica e sociológica ao patriarcado, revelando as distâncias e as tensões existentes entre o mito da mãe e as realidades vividas pelas mulheres. Foi neste mesmo período que algumas autoras inspiradas na psicanálise e nas suas próprias experiências como mães começaram a publicar livros que tratavam tanto da crítica à mitologia materna, quanto começavam a explicitar os conflitos vividos, expondo os sentimentos ambíguos da maternidade que não podiam ser verbalizados, como irritação, raiva, desapontamento, insatisfação e outros tantos que não se adequavam ao estereótipo da boa mãe (Bernard, 1974; Rich, 1986).

Mais recentemente as pesquisadoras feministas têm dado atenção à subjetividade materna, reconhecendo o impacto das representações da maternidade na produção feminista. Pesquisas realizadas a partir da década de 1990 enfocam as experiências diversificadas das mulheres, levando em consideração variáveis como a classe social, a raça, a etnia e, principalmente o gênero, mostrando outras representações da maternidade produzidas pelas mulheres a partir de suas experiências e expectativas (Bassin et al., 1994).

Seguindo esta nova abordagem feminista da maternidade, através da história oral procuro compreender como se constrói a memória das mães. A primeira dificuldade encontrada na coleta das narrativas orais deve-se às minhas próprias expectativas em relação à maternidade, projetadas para as mulheres que me receberam para as entrevistas. Esperava ouvir uma narrativa minuciosa, detalhista e emocionalmente intensa das minhas entrevistadas, pois ao comentar com algumas mulheres da segunda geração sobre meus interesses de pesquisa, muitas delas se colocaram como "candidatas" à entrevista porque tinham muito o quê contar. Verifiquei mesmo uma vontade ansiosa em narrar as experiências da maternidade para as mulheres mais jovens e foi com esta expectativa que iniciei as 
entrevistas com o grupo das mulheres mais velhas. Contudo, reconheço que não foi somente esta vontade falar das mulheres da segunda geração que me levou a esperar das outras mulheres histórias carregadas de acontecimentos e de emoções. Sem dúvida as minhas representações da maternidade precederam as narrativas das minhas entrevistadas. Esperava delas um roteiro que na verdade estava na minha imaginação: mães de muitos filhos, experiências marcantes e significativas sobre gravidez e partos, emoções intensas e contraditórias sobre amamentação e cuidados com os filhos; imagens da maternidade que não são delas, como pude verificar, mas que compõem o meu próprio quadro mental da maternidade no passado, certamente influenciada pela produção dos especialistas com a qual tenho mais intimidade do que as lembranças das senhoras idosas.

$\mathrm{Na}$ verdade deparei-me com um roteiro bastante diferente da memória materna para mulheres que viveram esta experiência na primeira metade do século XX. São narrativas de um trabalho árduo, da responsabilidade e de um certo orgulho de ter dado conta desta responsabilidade levando em consideração todas as dificuldades materiais com as quais tiveram que lidar no passado, comparadas com as facilidades do presente. São relatos desapaixonados da maternidade, lembrada como uma experiência pela qual as mulheres tinham que passar depois de casadas, nada mais. Era mais uma atribuição das mulheres que devia ser desempenhada da mesma forma que o trabalho.

As narrativas das experiências vividas pelas mulheres mais velhas são marcadas pelas reticências, pelos silêncios, pelas omissões. Os filhos que não vingaram, as dificuldades nas relações com as próprias mães, a alegação de que nada sabiam sobre sexo e contracepção são temas lembrados com dificuldade ou relegados para as zonas de esquecimento e omissão, pontuados pelos suspiros ou pelas frases "não lembro" e "não sei".

Articulada a esta forma de lembrar está a forma de narrar. De acordo com Alessandro Portelli alguns traços da oralidade que são perceptíveis pela audição, como a pausa, a velocidade da fala e o tom, são traços importantes porque revelam as emoções dos entrevistados, a forma como estão participando da narração e como esta os afeta (Portelli, 2003). As mulheres entrevistadas falam em tom muito baixo quando contam passagens de suas vidas difíceis de lembrar, aquelas mesmas que são pontuadas pelos silêncios e suspiros, como a morte dos filhos ou algum problema com os maridos. Quando lembram das festas, de passeios, de 
atividades que são valorizadas, como o trabalho ou alguma lembrança agradável da infância ou da juventude, o tom se eleva entre os risos.

Quanto à velocidade da narrativa, a gravidez e o parto são os assuntos narrados com frases mais curtas, sem detalhes, bem como a relação com as mães. Com exceção de uma entrevistada, que teve seis filhos e contou em detalhes cada gravidez e como foi cada um dos seis partos, as outras mulheres usaram poucas frases para lembrar de eventos diferentes que tiveram uma longa duração - em alguns casos a diferença entre o primeiro parto e o último é de quinze anos - ou seja, quando as perguntas são sobre a gravidez e o parto elas sintetizam as diferentes experiências na primeira gravidez e no parto do primeiro filho. A princípio essa economia de frases pode ser interpretada como esquecimento ou indisponibilidade da entrevistada em responder, mas não se trata nem de uma coisa, nem de outra. As entrevistas realizadas até o momento revelam que este traço da narrativa se deve à forma como estas mulheres constroem a memória daquela experiência e nesse sentido percebo que se trata, realmente, de uma característica de geração, pois ao confrontar os depoimentos parece que elas seguiram um roteiro na forma de organizar os acontecimentos relacionados à maternidade. Para elas a gravidez e os partos não são acontecimentos marcantes, emocionalmente intensos ou traumáticos, para que sejam organizados detalhadamente na narrativa. Percebi uma certa "naturalização" destas experiências, bem como das atividades relacionadas ao cuidado com bebês.

Não se pode esquecer que as mulheres da primeira geração não sofreram o impacto das teorias psicológicas sobre o vínculo mãe-filho, além do fato de que a maioria das entrevistadas teve cinco ou mais filhos e algumas trabalhavam para ajudar o marido ou faziam atividades para complementar a renda familiar, como o artesanato. A maternidade é vista como mais uma das "obrigações" da mulher, na verdade mais um trabalho e, como me disse uma das entrevistadas, o trabalho, depois de aprendido, é sempre a mesma coisa.

Ao narrar como casaram, engravidaram e tiveram seus filhos as mulheres da primeira geração demonstram sua adequação à ideologia da domesticidade. Suas memórias reforçam a divisão público/privado e a assimetria de poder entre os gêneros. Algumas lembram dos limites colocados à autonomia feminina, principalmente o poder dos homens da família em decidir o que era mais adequado para elas, do controle e da 
vigilância exercidos sobre suas vidas, como impedir que estudassem, que saíssem sozinhas, que namorassem. Apesar desta adequação aos papéis normativos de gênero pelos quais pautaram suas vidas, cabe salientar que, no que diz respeito à normatização da maternidade, essas mulheres se conduziram mais livremente, escutando as vizinhas e as parteiras - as mães são as grandes ausentes nessas narrativas - já que as idéias dos especialistas não as afetaram, pois elas não freqüentavam consultórios médicos, nem leram os livros de puericultura escritos pelos médicos para orientar as mães, com exceção de uma das entrevistadas, casada com um médico, que leu o famoso manual de puericultura escrito pelo Dr. Rinaldo De Lamare (1941).

Um aspecto a se ressaltar das narrativas foi a ausência das mães das entrevistadas nas suas memórias da maternidade. Quando lembram da infância a figura paterna ganha mais importância que a materna. O pai é lembrado de várias formas: pela rigidez, pelo trabalho árduo para sustentar a família, pelo carinho, pela amizade, destacando-se na memória das entrevistadas como alguém especial em suas vidas. As mães das entrevistadas são lembradas com respeito e reconhecimento pela capacidade que tiveram para vencer dificuldades materiais para criar muitos filhos, mas não mais do que isso. Não há demonstração de emoções quando falam das suas mães e nenhuma das entrevistadas demonstrou qualquer tipo de identificação com a figura materna ao lembrar de suas próprias experiências da maternidade. Novamente as minhas representações da maternidade foram frustradas, pois esperava ouvir relatos de uma aliança feminina entre mães, filhas, parteiras e parentes do sexo feminino em torno da gravidez, do parto e dos cuidados com as crianças.

Como interpretar esta ausência materna, este silêncio sobre as mães? Uma abordagem psicológica certamente será necessária, mas talvez uma primeira tentativa de explicação esteja na construção de gênero da memória. O modelo familiar no qual as entrevistadas foram criadas e no qual constituíram suas próprias famílias fundamentava-se na assimetria de gênero. Pais e mães eram igualmente merecedores do respeito e da obediência dos filhos, mas o poder era exercido inequivocamente pelo pai. A preeminência masculina na família certamente teve um impacto na visão de mundo das filhas, que desde pequenas aprenderam a respeitar, temer e valorizar seus pais e irmãos. Não pretendo enveredar por uma análise da divisão de poder entre pais e mães nas famílias tradicionais, mas defender 
a idéia de que houve um apagamento da figura materna frente à importância social do pai, do seu poder reconhecido dentro e fora da família. ${ }^{2}$

Lembrar da maternidade remete ao lugar onde as mulheres davam à luz. Esta geração de transição viveu duas situações: mulheres que deram à luz somente em casa, atendidas por parteiras, e mulheres que deram à luz em casa e também nas maternidades. Desde sua origem européia, as maternidades foram criadas para abrigar mulheres muito pobres que não tinham condições de dar à luz em suas casas e as mães solteiras. Devido às altas taxas de mortalidade materno-infantil e por atenderem as mulheres solteiras grávidas, por muito tempo as maternidades foram vistas como lugares ameaçadores, tanto para a saúde física de mães e filhos, quanto para a preservação moral das mulheres. No Brasil os médicos vinham defendendo, desde o final do século XIX, a necessidade de se organizar uma assistência pública que atendesse as mulheres pobres, construindo maternidades e protegendo as trabalhadoras grávidas. As autoridades não foram sensíveis às reivindicações dos médicos, tanto que a primeira maternidade criada no Brasil, a Maternidade Santa Isabel, que atendia mulheres pobres e escravas da cidade do Rio de Janeiro, funcionou apenas por dois anos, fechando suas portas em 1882 por falta de recursos. As maternidades começaram a ser construídas nas principais cidades brasileiras somente nas primeiras décadas do século XX, sendo a Maternidade das Laranjeiras a primeira instituição voltada para a clínica e o ensino, criada em 1904 no Rio de Janeiro e incorporada à Faculdade de Medicina em 1918 (Martins, 2000).

Tendo em vista esta ausência de políticas públicas para a maternidade no Brasil e a desconfiança com as poucas maternidades que existiam no início do século XX, o parto domiciliar atendido por parteira era a regra. A princípio os médicos não eram contrários ao parto domiciliar, pois sabiam que as escassas maternidades e as enfermarias de partos dos Hospitais de Caridade não eram suficientes nem adequados para o atendimento obstétrico. No entanto, criticavam com veemência o descaso das autoridades com o tipo de atendimento domiciliar que as mulheres mais

2 Agradeço a Joana Pedro e aos participantes do GT de Gênero do VII Encontro Nacional de História Oral realizado em Goiânia em 2004, pelas observações que fizeram sobre a construção de gênero da memória das mães. 
pobres recebiam, geralmente atendidas por parteiras leigas, sem nenhum tipo de treinamento supervisionado pelos médicos, vistas como verdadeiras ameaças à integridade física das parturientes e dos recém nascidos.

Todas as entrevistadas foram atendidas por parteiras, mesmo aquelas que tiveram alguns de seus filhos em maternidades. Ao lembrarem do parto falam da competência de suas parteiras, da atenção que recebiam não só por ocasião do parto, mas durante os primeiros dias do puerpério, quando as parteiras retornavam à casa de suas clientes para acompanhar o restabelecimento da mãe e a cicatrização do coto umbilical. Eram ocasiões também para ensinar a dar banho no bebê, amamentar, cuidar da alimentação da mãe e ajudá-la no que fosse necessário. Nas memórias maternas há um lugar especial de reconhecimento às parteiras, sempre lembradas pelo primeiro nome.

O fato de poderem contar com os serviços de uma parteira de reconhecida competência e confiança era fundamental para ter os filhos em casa, mas a classe social é um fator que não se pode desconsiderar no momento da escolha do lugar para dar à luz. Mulheres de classe média, com apoio da família, do marido e de empregadas domésticas, podiam dar à luz em casa mesmo havendo a possibilidade de ir para a maternidade. Já para as mulheres das classes populares ir para a maternidade podia ter outro significado, conforme pude perceber. Algumas delas contam que escolheram a maternidade para dar à luz porque era um lugar tranqüilo, limpo, bonito, claro e seguro. Mães de cinco, oito ou mais filhos, para elas ir para a maternidade significava também se afastar temporariamente da rotina dos afazeres domésticos e das responsabilidades com os outros filhos e o marido. Na maternidade eram atendidas pelas parteiras, pois raramente o obstetra fazia um parto normal; eram encaminhadas para uma enfermaria ou quarto no qual não precisavam se preocupar com a limpeza das roupas, nem a preparação da comida. O bebê recebia os cuidados de enfermagem e era levado para que a mãe amamentasse, retornando para o berçário. Na maternidade, pelo menos por alguns dias, estavam afastadas das preocupações que teriam caso tivessem dado à luz em casa.

Há, no entanto, o outro lado dessa escolha, pois como os próprios médicos lembravam, o parto domiciliar permitia que as mulheres não se afastassem de casa, dos outros filhos e do marido, mantendo a ordem doméstica, mesmo que fragilizada pelo parto. Nas entrevistas percebi que as duas opções tinham seus prós e contras, mas para as mulheres pobres 
a hospitalização podia ser uma boa escolha, principalmente se tinham parentes que podiam cuidar dos outros filhos enquanto estivessem ausentes. Não se pode esquecer que as mulheres da primeira geração não tinham muita escolha, pois o número de leitos em maternidades era escasso até a metade do século XX, mesmo em centros urbanos maiores. A política de saúde materno-infantil no Brasil começou a ser formulada nos anos 1930 e executada a partir da década de 1940 atendendo primeiro as demandas de centros urbanos maiores como Rio de Janeiro, São Paulo, Belo Horizonte, Salvador e Recife. Só mais tarde, já na década de 1950, cidades menores começaram a contar com os postos de puericultura e maternidades.

Estas mulheres também não foram leitoras dos manuais de puericultura, nem das revistas que tratavam de assuntos relativos à criação dos filhos. Nenhuma da entrevistadas conheceu estas publicações, com exceção de duas delas. A primeira, que deu à luz apenas na maternidade, afirmou ter ouvido falar do livro do médico pediatra Rinaldo De Lamare, mas não chegou a ler, enquanto a outra, a esposa de médico que deu à luz na maternidade e também em casa, como já comentado acima, leu o livro e disse que ele foi muito útil, especialmente as informações sobre as doenças infantis.

Quando indagadas sobre como criaram os filhos, se receberam algum conselho ou ajuda, responderam de forma evasiva, dizendo que nada sabiam e que se guiaram pelo bom senso, pelo que consideravam certo. Nenhuma das entrevistadas lembrou da ajuda ou dos conselhos da própria mãe, nem por ocasião do casamento, nem de seus partos. Salientaram sua ignorância nas coisas práticas da vida, como saber cozinhar e cuidar das crianças, tendo que se adaptar às circunstâncias. Quando lembram da ajuda de alguém, geralmente é da parteira, como vimos.

Uma das entrevistadas foi parteira também. Mãe de cinco filhos falecidos em decorrência do "mal de sete dias", ela pouco falou da gravidez e dos partos, afinal eles não resultaram na vida, mas na morte dos filhos. Sua lembrança é da experiência dos partos que realizou, ajudando a colocar no mundo centenas de crianças, lembrança esta da qual tem muito orgulho. Ela não chegou a ser diplomada, pois fez um curso de

3 Mal de sete dias é o nome popular de uma forma de tétano que afeta crianças recém-nascidas devido ao uso de instrumentos cortantes para seccionar o cordão umbilical. 
atendente de enfermagem numa maternidade da cidade de Caruaru, Pernambuco, mas o que aprendeu foi suficiente para ajudar mulheres pobres como ela, quando sozinha, com uma filha para criar, migrou para o norte do Estado do Paraná para trabalhar na colheita de algodão e depois de café. Esta mulher que fez tantos partos até envelhecer e se aposentar, é uma defensora do parto hospitalar. Quando perguntei do porquê desta escolha, se ela sempre atendeu parturientes em casa, respondeu que era mais seguro, mais higiênico e que as mulheres seriam bem atendidas na maternidade. Sua única filha deu à luz em maternidade e ela não assistiu os dois partos de seus netos.

Outra entrevistada queria ser parteira na juventude. Descendente de imigrantes ucranianos saiu da colônia onde vivia com a família em Santa Catarina para fazer o curso de enfermagem na Maternidade Victor Ferreira do Amaral, em Curitiba. Decidida a se casar, não terminou o curso e nunca fez nenhum parto, mas teve sete filhos com uma única parteira, todos em casa. Esta entrevistada é uma defensora do parto domiciliar, por considerar mais confortável e pelo fato da mulher não se afastar do marido e dos outros filhos. Indagada sobre a supremacia do parto hospitalar nos dias atuais, disse que isso se deve à desinformação das mulheres que têm medo de dar à luz em casa, além da indisponibilidade de parteiras para atender as mulheres em domicílio. Todas as suas filhas deram à luz em maternidades e ela assistiu os partos.

Nenhuma das entrevistadas teve um parto mal sucedido por ter sido atendida em casa e só uma narrou um parto muito difícil no qual a parteira chamou o médico, sendo necessária a anestesia com o clorofórmio, chegando a bom termo. As lembranças desses partos são muito vagas; algumas relatam as fortes dores, a demora para a criança nascer, as orações das mulheres presentes e o trabalho da parteira, mas de forma geral, não entram em detalhes e, como já salientado, acabam por resumir os diferentes partos num só, como se todos tivessem sido iguais, não havendo nada de notável para ser lembrado.

Analisando cada entrevista ou mesmo o conjunto, o que se percebe é uma narrativa desapaixonada da maternidade. Todas são unânimes em afirmar que a maternidade era uma experiência pela qual as mulheres tinham que passar e que não havia nada de especial nisso. A diferença estava nas dificuldades que enfrentaram com os maridos ou com os filhos, devido a problemas como doenças, violência, embriaguez ou desemprego. 
Para elas a maternidade era, literalmente, trabalho. Primeiro com os filhos, para prover o bem estar físico, preparando a alimentação, cuidando do vestuário, dando banho, cuidando quando doentes, depois com a casa, dando conta da cozinha, da limpeza, lavar e passar roupas, bem como contribuir para a renda familiar costurando ou bordando. Como disse uma das entrevistadas, o dia todo era tomado pelo trabalho e este, sim, é narrado em detalhes.

Ao contar como trabalhavam, percebe-se uma ponta de orgulho por terem conseguido desempenhar bem suas atividades de donas de casa e mães. Não tendo as facilidades da tecnologia do lar com as quais suas filhas e netas contam hoje em dia, o trabalho doméstico era, sem dúvida, muito mais penoso e demorado. O esforço físico que atividades como lavar e passar roupa exigiam também era muito maior, como lembram as entrevistadas. Sem contar com empregadas domésticas para realizar este trabalho, havia uma sobreposição das atividades domésticas ao cuidado dos filhos, o que contribuía para associar a maternidade ao trabalho, já que as atividades eram desempenhadas pela mesma pessoa e ao mesmo tempo.

Embora esta análise seja parcial, as mulheres que fazem parte da geração que passou pela experiência da maternidade na primeira metade do século XX constroem uma imagem da maternidade associada à responsabilidade e ao sofrimento, mais do que à felicidade. Sem dúvida que a condição de mulheres idosas vivendo com filhos ou filhas e a solidão da velhice desempenham um importante papel na construção da memória da maternidade, mas acredito que não seja o suficiente para explicar tal imagem. Todas as entrevistadas são de classes populares ou de classe média sem muitos recursos, portanto tiveram que lutar contra uma série de problemas para sobreviver e manter suas famílias. Nesse contexto marcado pelas dificuldades materiais e pelo trabalho cotidiano, as mulheres tinham que dar conta de muitas coisas ao mesmo tempo e estavam muito distantes daquelas representações românticas da maternidade tão presentes no imaginário social, como a mãe amorosa e sempre disponível. Não estou dizendo que as mães não amassem seus filhos ou que pouca atenção dessem a eles, mas que a maternidade foi vivida de maneira bastante diferente pelas mulheres reais, pelas entrevistadas. A própria definição de amor maternal, como bem sabemos, é uma construção cultural que diz muito mais do que a sociedade espera das mulheres do que dos sentimentos das mesmas em relação aos seus filhos. 
Para as mulheres a maternidade pode significar muita coisa, ou pode ter roteiros bastante diferentes, como pude perceber através dos relatos das entrevistadas. Para elas foi uma experiência que exigiu um engajamento físico muito grande, um trabalho, como dizem. A construção da memória dessas mulheres mostra como estavam distantes dos modelos idealizados da mãe desvelada e emocional, envolvidas com a manutenção de suas famílias e a resolução de problemas do cotidiano. A maternidade era mais uma atividade que deviam desempenhar na sua vida de mulheres, agravada pela responsabilidade de criar os filhos. Por isso, talvez, todas enfatizem o peso da responsabilidade e vejam na maternidade não o depositário de sentimentos nobres e específicos das mulheres, mas a faina de produzir e criar filhos.

\section{Referências bibliográficas}

BASSIN, Donna; HONEY, Margaret; KAPLAN, Meryle (ed.). Representations of motherhood. New Haven/London: Yale University Press, 1994.

BERNARD, Jessie. The future of motherhood. New York: Dial, 1974.

DE LAMARE, Rinaldo. A vida do bebê. Rio de Janeiro, Bloch, 1941.

EHRENREICH, Bárbara; REICH, Deidre. Para seu próprio bem: 150 anos de conselhos de especialistas para as mulheres. Rio de Janeiro: Editora Rosa dos Tempos, 2003.

FORNA, Aminatta. Mãe de todos os mitos: como a sociedade modela e reprime as mães. Rio de Janeiro: Ediouro, 1999.

KNIBIEHLER, Yvonne. Histoire dês mères et de la maternité en Occident. Paris: PUF, 2000.

MARTINS, Ana Paula Vosne. A medicina da mulher: visões do corpo feminino na constituição da obstetrícia e da ginecologia no século XIX. Campinas: UNICAMP, Departamento de História-IFCH (Tese de Doutorado), 2000.

PORTELLI, Alessandro. What makes oral history different. In: PERKS, Robert; THOMSON, Alistair (ed.). The oral history reader. London/New York: Routledge, 2003.

RICH, Adrienne. Of womam born: motherhood as experience and institution. Tenth anniversary edition. New York: W.W. Norton\&Company, 1986.

RUDDICK, Sarah. Maternal thinking. Boston: Beacon Press, 1989.

. Thinking mothers/conceiving birth. In: BASSIN, Donna; HONEY, Margaret; KAPLAN, Meryle (ed.). Representations of motherhood. New Haven/London: Yale University Press, 1994.

SANGSTER, Joan. Telling our stories: feminist debates and use of oral history. In: PERKS, Robert; THOMSON, Alistair (ed.). The oral history reader. London/New York: Routledge, 2003. 
THEBAUD, Françoise. Quand nos grand-mères donnaient la vie: la maternité en France dans l'entre-deux-guerres. Lyon: PUL, 1986.

TRONTO, Joan C. Care as a political concept. In: HIRSCHMANN, Nancy; STEFANO, Christine (ed.). Revisioning the political: feminist reconstructions of tradicional concepts in western political theory. Boulder: Westview Press, 1996.

Resumo: Este artigo trata da produção da memória materna para uma geração de mulheres que viveu a experiência da maternidade no período em que o Estado brasileiro deu início às políticas de saúde e assistência materno-infantil, entre as décadas de 1930 e 1940. São mulheres que estão, atualmente, com mais de 75 anos e que narram suas experiências da gravidez, do parto e da criação dos filhos, apresentando uma outra versão da história da maternidade, diferente daquela produzida pelos especialistas. As memórias dessas mães que hoje são avós e bisavós apresentam elementos narrativos e versões das experiências individuais de processos sociais e culturais suficientes para se iniciar uma discussão sobre a construção da memória e também da metodologia da história oral.

Palavras-chave: memória; mães; subjetividades femininas.

\title{
Maternal Memories: Motherhood Experiences in the Transition from Home to Hospital Childbirth
}

\begin{abstract}
This article deals with the production of maternal memories by a generation of women who experienced motherhood during the period in which the Brazilian government began its health and mother-child assistance policies, between the 1930s and 1940s. Those women, currently over 75 years of age, narrate their experiences during pregnancy, labor and the raising of their children, presenting another version of the history of maternity different from that rendered by the specialists. The memories of these mothers, now grandmothers and greatgrandmothers, present enough narrative elements and aspects of individual experiences of social and cultural processes to yield a discussion on the construction of memory and also on the methodology of oral history.
\end{abstract}

Keywords: memory; mothers; feminine subjectivity. 
